\title{
KARL POPPER O LA VIGENCIA DEL PROYECTO CLÁSICO DE CIENCIA MODERNA.
}

\section{LA CUESTIÓN DE LAS CIENCIAS SOCIALES}

Amancio VÁZQUEZ ${ }^{1}$

\section{Resumen:}

A partir del planteamiento de tres tesis que sostienen la hegemonía de las posiciones epistemológicas "objetivistas" (aún en ciencias sociales) por parte de las instituciones que oligopolizan la producción científica, el artículo propone la apertura de líneas de debate respecto a: la influencia de la obra de Karl Popper en el mundo científico; la vigencia del

${ }^{1}$ Lic. En Ciencia Política. Docente UNR- UNL amanciovazquez@,hotmail.com

Fecha de recepción del artículo : Abril 2012

Fecha de evaluación: Mayo 2013 
proyecto tradicional positivista con qué se originó la ciencia moderna y el panorama epistemológico de las ciencias sociales en relación con las posiciones "objetivistas".

Palabras clave: objetivismo- proyecto tradicional positivista- Karl Popper- ciencias sociales.

\begin{abstract}
:
The papers considers three epistemological "objectivistic" thesis proposed for science in general-including social sciences- supported by "oligopolistic" institutions in this field, and then deals with: the influence of Karl Popper in the scientific field; the importance of the traditional positivistic project on which modern science was built; and the epistemological future of social sciences in connection with objectivistic standpoints.
\end{abstract}

Key words:objectivism - traditional positivist project-Karl Popper - socialsciences.

Résumé: À partir de l'approche de trois thèses qui maintiennent l'hégémonie des positions épistémologiques «Objectivistes » (même dans les sciences sociales) par les institutions qui font l'oligopole de la production scientifique, l'article propose l'ouverture de lignes de débat en ce qui concerne: l'influence des travaux de Karl Popper dans le monde scientifique; la validité du projet positiviste traditionnelle à partir duquel est née la science moderne et le panorama épistémologique des sciences sociales par rapport à les positions «objectivistes».

Mots clés: objectivisme - projet traditionnel positiviste - Karl Popper - sciences sociales.

\title{
1. Introducción
}


Este artículo sostiene que la concepción dominante de la ciencia en la actualidad coincide en sus fundamentos con la postura epistemológica de Karl Popper. Por otro lado, esta posición epistemológica que podría caracterizarse como "objetivista" no difiere, en sus supuestos básicos, de la concepción tradicional positivista con que se originó la ciencia moderna hacia finales del S. XVII.

En el campo de las ciencias sociales, si bien el panorama es más complejo debido a la existencia de un horizonte epistemológico fragmentado, es posible observar que el grueso de las instituciones que oligopolizan la producción científica (universidades, consejos de investigación estatales y privados, fundaciones y sociedades científicas) promueven investigaciones con tales supuestos objetivistas.

A partir de tres tesis que refieren a estas cuestiones, este artículo propone abrir líneas de debate respecto a: la influencia de la obra de Karl Popper en la comunidad científica; la vigencia del proyecto tradicional positivista con qué se originó la ciencia moderna y el panorama epistemológico de las ciencias sociales en relación con la cuestión de las posiciones objetivistas.

\section{Tres tesis}

\section{Tesis 1: En términos generales el conjunto de la ciencia hoy, funciona de acuerdo al modelo popperiano.}

La postura epistemológica de Karl Popper es sin dudas, y pese a todas las críticas que se le han hecho $^{2}$, la que más se aproxima a la concepción dominante de la ciencia actual (ciencia en

\footnotetext{
${ }^{2}$ Algunos grandes ejemplos son: la escuela histórica alemana; la escuela constructivista francesa; el escepticismo "anarquista" de Paul Feyerabend (1974); la "doble hermenéutica" de Anthony Giddens (1987); los abordajes hermenéuticos Ricoeur (1963, 1981 y 1985); la hermenéutica intersubjetiva de Habermas (1988) ; la hermenéutica fenomenológico-interpretativista de Hans Gadamer (1997); etc.
} 
términos generales). Dicho de otro modo, pese a toda el agua que ha corrido bajo el puente, no es una hipérbole sostener que el conjunto de la ciencia hoy responde básicamente al modelo falsacionista popperiano.

Cuando aquí se hace referencia al "conjunto de la ciencia hoy en términos generales" se está pensando en dos dimensiones de la ciencia: 1) la concepción que las actuales sociedades occidentales tienen del término -concepto y 2) la lógica de la investigación que las distintas disciplinas usan para producir conocimiento científico.

Más allá de la simplificación que implica toda generalización. Aquí se sostiene que tiene sentido hacer referencia tanto a un concepto de ciencia comúnmente aceptado, como a un conjunto de modos de investigar -lógica de la investigación-. Esta generalización está aun mayormente justificada en cuanto que las prácticas científicas son oligopolizadas por un conjunto pequeño de instituciones, por lo que en última instancia, ciencia va a ser lo que las instituciones científicas producen.

Las ciencias exactas (lógico -formales) y las ciencias sociales no se acoplan con toda comodidad al término-concepto de "ciencia general", que, siguiendo a esta "tesis 1" funciona de acuerdo al modelo popperiano. De las primeras, este artículo no se ocupa, pero hasta donde aquí se ha estudiado puede decirse que no utilizan el modelo popperiano. De las segundas, las ciencias sociales, se tratará en la "tercera tesis", pero desde ya se adelanta que, con algunas salvedades, se encuadran en este modelo.

\section{El falsacionismo popperiano (primeras palabras)}

Popper sostenía que la ciencia es un producto humano cuyo fin es resolver problemas a través del método de "ensayo y error". En este sentido, la ciencia no ha de entenderse como algo sustancialmente distinto del conocimiento vulgar, la diferencia radica en que la ciencia procede sistemáticamente y de manera rigurosa. Dentro del método del "ensayo y error" Popper 
proponía que no había que entusiasmarse demasiado con los ensayos acertados; había que tomarlos como éxitos relativos y aceptarlos sólo provisoriamente; pues escapa a las posibilidades humanas saber "cómo son las cosas". En cambio a los ensayos fallidos había que descartarlos definitivamente, pues sí está dentro de las posibilidades humanas saber "cómo las cosas no son". Y por eso mismo era posible entusiasmarse con tales ensayos fallidos; porque a través del descarte seguro de los errores; a través de saber "cómo las cosas no son", es posible acercarse cada vez más a lo que se busca. La única condición es mantenerse en movimiento.

\section{La ciencia actual}

Sin dudas la postura popperiana expresada en el párrafo anterior representa un cuadro bastante preciso de la filosofía de la ciencia actual (según la entienden nuestras sociedades occidentales y según la practican las instituciones que oligopolizan la investigación científica). Un saber con sentido práctico, distinto de las especulaciones filosóficas sobre el fondo de los seres. Un conocimiento que utiliza una metodología basada en supuestos (hipótesis) que han de ser puestas a prueba mediante el "ensayo y error"(experimentos u otras formas de control impersonal de variables); logros provisorios y limitados (carácter hipotético de las teorías); desecho de teorías anteriores (actualización constante) y actividad sin pausa (dinámica constante de la investigación científica).

A continuación, se presenta el cuadro $\mathrm{N}^{\mathrm{o}} 1$ que ilustra algunas de estas similitudes básicas. El mismo compara el falsacionismo popperiano con el diseño de una investigación científica según lo exigen las instituciones que oligopolizan la producción científica. La primera columna del cuadro fue elaborada a partir de las obras de Karl Popper y la segunda a partir de una síntesis de algunos de los requisitos para proyectos de investigación y trabajos científicos (aún para ciencias sociales) que aparecen como obligatorios en instituciones productoras de ciencia como CONICET, distintos doctorados acreditados por CONEAU y trabajos finales de carreras de universidades públicas y privadas.

\section{Cuadro $\mathbf{N}^{0} 1$}




\begin{tabular}{|c|c|}
\hline Falsacionismo popperiano & $\begin{array}{l}\text { Diseño de una investigación actual según } \\
\text { las instituciones que oligopolizanla } \\
\text { producción de conocimiento científico }\end{array}$ \\
\hline $\begin{array}{l}\text { La ciencia comienza por problemas: } \\
\text { "Tanto las ciencias naturales como las ciencias } \\
\text { sociales parten siempre de problemas..." (La } \\
\text { Responsabilidad de Vivir, cap.1); "...el } \\
\text { conocimiento no parte de percepciones u } \\
\text { observaciones o de la recopilación de datos o } \\
\text { hechos, sino que comienza, más bien, a partir de } \\
\text { problemas..." (En búsqueda de un mundo mejor, } \\
\text { cap. 5, cuarta tesis). }\end{array}$ & $\begin{array}{l}\text { Problema de investigación: } \\
\text { En términos generales todos los diseños de } \\
\text { proyectos de investigación parten de } \\
\text { transformar el tema de la investigación en } \\
\text { un problema susceptible de ser investigado } \\
\text { empíricamente. Más aún suele exigirse que } \\
\text { el problema sea formulado claramente } \\
\text { como una pregunta a partir de la cual se } \\
\text { inicia todo el proceso de investigación. }\end{array}$ \\
\hline $\begin{array}{l}\text { A la luz de una teoría: } \\
\text { "Las teorías son redes que lanzamos para apresar } \\
\text { aquello que llamamos "el mundo": para } \\
\text { racionalizarlo, explicarlo y dominarlo. Y tratamos } \\
\text { de que la malla sea cada vez más fina" (La Lógica } \\
\text { de la Investigación Científica; Capítulo Tercero; } \\
\text { Teorías) "No existe nada semejante a una ciencia } \\
\text { puramente observacional; sólo hay ciencias en las } \\
\text { que teorizamos de forma más o menos consciente } \\
\text { o crítica..." (En búsqueda de un mundo mejor, } \\
\text { cap. 5, vigesimoprimera tesis). }\end{array}$ & $\begin{array}{l}\text { Marco teórico: } \\
\text { Toda investigación ha de contar con un } \\
\text { marco teórico o conceptual claramente } \\
\text { especificado que remite a las concepciones } \\
\text { previas desde las cuales el investigador } \\
\text { construye su objeto ya que no hay otra } \\
\text { forma de aproximarse a la realidad. }\end{array}$ \\
\hline Método hipotético deductivo (ensayo y error): & Hipótesis: \\
\hline
\end{tabular}




\begin{tabular}{|c|c|}
\hline $\begin{array}{l}\text { "Al igual que las ciencias naturales, el método de } \\
\text { las ciencias sociales radica en ensayar posibles } \\
\text { soluciones para los problemas de los cuales parten } \\
\text { nuestras investigaciones. Se proponen y critican } \\
\text { soluciones..." (En búsqueda de un mundo mejor, } \\
\text { cap. 5, vigesimoprimera tesis). }\end{array}$ & $\begin{array}{l}\text { Son las respuestas tentativas al problema } \\
\text { de investigación. Las cuales se intentarán } \\
\text { controlar mediante el control impersonal } \\
\text { de las variables. }\end{array}$ \\
\hline $\begin{array}{l}\text { Control crítico de las teorías: } \\
\text { "Si la solución propuesta es susceptible de crítica } \\
\text { objetiva, intentamos refutarla, pues toda crítica } \\
\text { consiste en intentos de refutación (En búsqueda de } \\
\text { un mundo mejor, cap. 5, sexta tesis, B.). } \\
\text { Teorías provisorías: "Si resiste la crítica, lo } \\
\text { aceptamos provisionalmente; y, desde luego, lo } \\
\text { aceptamos como digno de seguir siendo discutido } \\
\text { y criticado" (En búsqueda de un mundo mejor, } \\
\text { cap. } 5 \text {, sexta tesis, D). }\end{array}$ & $\begin{array}{l}\text { Metodología: } \\
\text { Es el camino o estrategia para el control } \\
\text { impersonal de las hipótesis propuestas. } \\
\text { Claramente la manera de intentar refutar } \\
\text { las respuestas tentativas propuestas. }\end{array}$ \\
\hline
\end{tabular}

Tesis 2: La concepción popperiana de la ciencia actual mantiene el grueso de los supuestos
que tuvo la ciencia moderna positivista desde sus orígenes (hacia finales del siglo XVII).

No se dice aquí que el falsacionismo propuesto por Popper sea igual a la concepción positivista de la ciencia moderna del siglo XVII. Lo que si se dice es que el pensamiento epistemológico de Karl Popper supone la versión actual, viva y vigorosa del proyecto clásico de ciencia moderna. Dicho de otra forma, esta segunda tesis sostiene que: si la ciencia clásica moderna, el producto más célebre del proyecto racionalista (occidental y burgués) de los siglos de la ilustración, encuentra sus ancestros remotos en la antigua Grecia; en la figura de Karl Popper encuentra buena parte (sino toda) de su forma actual. 
Esta idea, si bien goza de cierta aceptación por quienes se dedican a estudiar a la ciencia, pocas veces es enunciada expresamente y más bien queda tácita cuando se hace un desarrollo explicativo de la obra popperiana. Para los propósitos de este trabajo, sin embargo, es fundamental explicitarla con toda precisión. Para ello se va a hacer referencia a lo que se entiende aquí por "ciencia clásica moderna" y luego se volverá sobre "el falsacionismo popperiano".

\section{Ciencia clásica moderna}

Por "ciencia clásica moderna" aquí se entiende a aquel sistema de conocimiento que partiendo de una epistemología "objetivista" (donde el papel del sujeto cognoscente es soslayado ante el protagonismo que cobra el objeto a conocer) pretende, a través de una razón única e universal, alcanzar un conocimiento verdadero de la realidad que sirva tanto para explicarla como para modificarla en provecho de quienes lo utilicen. Es decir un conocimiento que habilite la apropiación instrumental del mundo. Esta idea de ciencia es, más allá de algunos límites que se le han reconocido posteriormente a sus pretensiones, la visión arquetípica que se tiene de la ciencia en la actualidad. Lo que Mario Heler denomina historia oficial de la ciencia (Heler: 2005). Efectivamente, más allá de que hoy día los alcances y ciertas pretensiones de la ciencia expresadas en el párrafo anterior se han relativizado (en especial la idea de verdad); el conocimiento que actualmente se auto adjudica excelencia epistemológica y neutralidad valorativa; o lo que Heler llama garantía de verdad y objetividad (Heler: 2005) se inscribe con claridad en esta tradición de pensamiento que se inicia hacia el siglo XVII.

Con tan augustos pergaminos esta ciencia se presentó a si misma cómo el saber supremo y reclamó, como tal, su lugar de privilegio dentro de la sociedad. Una posición de domino que en el siglo XX fue alcanzada y consolidada, Y que, más allá de las críticas que suele recibir, está muy lejos de verse realmente amenazada. Piénsese no sólo en el estatus y dignidad que la ciencia y su simbología ocupa en nuestras sociedades sino en cómo esta interviene (o se pretende que intervenga) en todo el complejo entrazado de interacciones humanas de intercambio para reproducir la vida económica y social. Más aún; casi podría sostenerse sin caer en la exageración que en la actualidad el propio vocablo conocimiento, en sentido propio, ha 
quedado reducido al concepto de conocimiento científico. Cómo la única forma de conocer socialmente legitimada.

\section{EI falsacionismo popperiano (segundas palabras)}

Los aportes y modificaciones hechas a la lógica de la investigación científica por Karl Popper a partir de $1934^{3}$ de ninguna manera rompen con los postulados de esta visión clásica moderna, oficial o arquetípica de concebir a la ciencia. Por el contrario a ellos se debe, en grandísima parte, su vigorosa subsistencia en nuestros días. Preocupado por las deficiencias más evidentes del modelo científico clásico, en especial la imposibilidad lógica del verificacionismo ${ }^{4}$ basado en el razonamiento inductivo ${ }^{5}$; Popper idea un método falsacionista que permitiría salvar las posibilidades de la razón humana y por tanto mantener en pie al proyecto moderno.

Resumiendola postura, puede decirse que el falsacionismo de Popper lo que hace es desplazar las posibilidades de la razón humana, de la instancia de la construcción del conocimiento científico (como hacían los primeros positivistas) a la instancia del control del mismo. La fórmula lógica de éste planteo es la argumentación del modus tollen, que establece que si bien es imposible formular generalizaciones universales a través de un número finito de observaciones particulares; si es posible a partir de un sólo hecho particular establecer la falsedad de la generalización. Dicho de otra manera las posibilidades de la ciencia no están en la construcción del conocimiento sino en su control crítico. De aquí el nombre de "racionalismo crítico" con que se conoce su escuela.

\footnotetext{
${ }^{3}$ Año de publicación de la primera edición de la "Lógica de la Investigación Científica" de K. Popper.

${ }^{4}$ El verificacionismo sostiene que los enunciados científicos se pueden verificar (tomar como verdaderos) a partir de la observación empírica y utilizando un razonamiento inductivo.

5 Previamente a Popper, David Hume (1711 - 1776) puso en evidencia la debilidad lógica del pensamiento inductivo, que consiste en la imposibilidad de establecer principios generales a partir de la observación de un número finito de hechos particulares.
} 
En un claro optimismo epistemológico y sin soltarse de los patrones del racionalismo clásico, Karl Popper ve el vaso medio lleno y hace del citado modus tollens una salida para la razón. Es decir, la ciencia mantiene sus posibilidades y su excelencia epistemológica pero no ya para afirmar el conocimiento sino para negarlo. Popper entonces, conserva todos los supuestos clásicos de la ciencia positivista: utilización de una razón universal, monismo metodológico, objetividad, neutralidad valorativa, etc. Pero los desplaza del momento de la construcción del conocimiento (contexto de descubrimiento) al momento de su control crítico (contexto de justificación). Resulta importante aclarar que el contexto clave es para Popper el de justificación pues es allí donde la razón tiene sus posibilidades. Es allí el topus donde la mera opinión se transforma en ciencia.

El siguiente cuadro $\mathrm{N}^{\mathrm{o}} 2$ ilustra esta separación que establece el falsacionismo popperiano entre un contexto de descubrimiento y otro de justificación.

Cuadro $\mathrm{N}^{\circ} 2$

\begin{tabular}{|l|l|}
\hline \multicolumn{2}{|c|}{ Falsacionismo popperiano } \\
\hline Contexto de descubrimiento & Contexto de justificación \\
\hline Multiplicidad de fuentes de conocimiento & Razón universal única fuente de control \\
\hline Multiplicidad de métodos & $\begin{array}{l}\text { Monismo metodológico: } \\
\text { deductivo }\end{array}$ \\
\hline Subjetividad & Objetividad \\
\hline Involucramiento & Neutralidad valorativa \\
\hline
\end{tabular}

El quid de la cuestión en lo que atañe a la problemática de en qué medida la propuesta de Popper se aleja o no del modelo clásico de ciencia moderna, es evaluar los efectos que la 
separación popperiana entre un contexto de descubrimiento (ruptura) y un contexto de justificación (conservación) producen en la concepción de ciencia.

Según la idea que se sostiene en este artículo la concepción de ciencia que propone Popper, si bien es más modesta que la planteada por la ciencia clásica moderna, sigue manteniendo el grueso de sus supuestos por lo que el distanciamiento es mínimo. Se trata de una concepción de ciencia en extremo fuerte (el falsacionismo supone la posibilidad de negar teorías de forma absolutamente segura y objetiva). A través de la crítica racionalal conocimiento,que presupone una correcta utilización (método único) de la razón humana (concebida a la manera de la ciencia clásica como universal), es posible conocer el mundo (si bien por vía negativa) y decidir objetivamente la mejor de las teorías. Acaso el punto que implica la mayor continuidades que, tanto para la ciencia clásica como para el falsacionismo popperiano, el sujeto que conoce no tiene un papel decisorio en el proceso de conocer. La ciencia clásica objetivista, sostenía una noción de verdad especular, donde el objeto era aprendido pasivamente por el sujeto; y en la postura popperianasi bien el sujeto tiene preponderancia en el contexto de producción del conocimiento no lo tiene en el contexto de justificación del mismo, que cómo ya se ha visto, es el fundamental o clave en el modelo del racionalismo crítico. El propio Popper (Popper: 1994) explicita que la suya es "una epistemología sin sujeto cognoscente".

La salida falsacionista popperiana otorga un punto de apoyo sólido a la razón humana (concebida en idénticos términos que en la época de la ilustración); un lugar donde es posible hacer pie firmemente. Esta salida, tiene la trascendental consecuencia de superar el nihilismo epistemológico. La razón, por medio de la ciencia, es capaz de superar la más demoledora quizá de todas las críticas a que fue sometida, la imposibilidad de la verificación. Tanto ahora como a finales del siglo XVII la ciencia seguirá siendo aquella maravillosa herramienta humana que permite conocer de la mejor manera posible y que además facilita la apropiación instrumental del mundo. La verificación ha dado paso a la falsación que si bien es en su alcance más modesta; es, desde el punto de vista de la lógica, irreprochable. 
El proyecto moderno positivista de la ciencia clásica, aquel que encontró su germen en la Grecia antigua y se lanzó a conquistar el mundo a partir de finales del siglo XVII ha sido salvado gracias al racionalismo crítico. La economía capitalista y la ideología política liberal ${ }^{6}$ sus grandes impulsores siguen, hoy cómo ayer, apoyados y apoyándose en este modelo de ciencia, formando parte indisoluble de una manera particular de comprender y relacionarse con el mundo: la modernidad.

El cuadro siguiente destaca algunas de las importantes características que se mantienen tanto en el modelo clásico de ciencia como en el actual o popperiano.

\section{Cuadro $\mathbf{N}^{0} 3$}

\begin{tabular}{|l|l|}
\hline Ciencia clásica moderna & Falsacionismo popperiano \\
\hline $\begin{array}{l}\text { Sistema de conocimiento racionalmente } \\
\text { justificado a través de la verificación. }\end{array}$ & $\begin{array}{l}\text { Sistema de conocimiento racionalmente } \\
\text { justificado a través de la falsación. }\end{array}$ \\
\hline Monismo metodológico (inducción) & $\begin{array}{l}\text { Monismo metodológico (hipotético- } \\
\text { deductivo) }\end{array}$ \\
\hline Capaz de alcanzar la verdad. & Capaz de aproximarse a la verdad. \\
\hline $\begin{array}{l}\text { Capaz de apropiarse instrumentalmente del } \\
\text { mundo. }\end{array}$ & $\begin{array}{l}\text { Capaz de apropiarse instrumentalmente } \\
\text { del mundo. }\end{array}$ \\
\hline $\begin{array}{l}\text { Capaz de establecer la verdad del conocimiento } \\
\text { de forma segura. }\end{array}$ & $\begin{array}{l}\text { Capaz de establecer la falsedad del } \\
\text { conocimiento de forma segura. }\end{array}$ \\
\hline $\begin{array}{l}\text { Capaz de generar un conocimiento legalista; } \\
\text { universal y objetivo. }\end{array}$ & $\begin{array}{l}\text { Capaz de generar un conocimiento } \\
\text { legalista; universal y objetivo aunque } \\
\text { provisorio. }\end{array}$ \\
\hline
\end{tabular}

${ }^{6}$ Karl Popper adhería explícitamente a ambos. 
Tesis 3: En las ciencias sociales el grueso de las investigaciones, promovidas por las instituciones que oligopolizan la producción científica, se mantienen, aunque muchas veces ocultándolo, dentro de estos supuestos epistemológicos tradicionales.

En las ciencias sociales los supuestos clásicos de la ciencia, es decir las posiciones objetivistas, han sido más duramente cuestionados que en las otras ciencias. Por otro lado, otras posturas epistemológicas distintas, como las hermenéuticas han logrado alcanzar posiciones fuertes en el campo. Por lo que sin duda la identificación entre el falsacionismo popperiano y las ciencias sociales resulta más complejo.

Ahora bien, pese a toda esta agua que ha corrido bajo el puente; en las ciencias sociales actuales, al menos en lo que hace a la investigación empírica, las posiciones tradicionales objetivistas, no solo mantienen su fuerza epistémica, sino que son incluso el paradigma dominante. Puede observarse que en las instituciones que producen ciencia social los protocolos para diseñar investigaciones exigen la utilización de epistemologías tradicionales objetivistas que, según se ha visto en estas páginas, responden al modelo popperiano y por tanto no se alejan del proyecto clásico de ciencia moderna.

Para ilustrar estos puntos se hará a continuación una breve síntesis del derrotero epistemológico de las ciencias sociales y luego una aclaración respecto de las instituciones productoras de ciencia.

\section{Derrotero de la epistemología de las ciencias sociales}

Las primeras experiencias de ciencias sociales institucionalizadas se dan hacia finales del S.XIX en occidente, en un momento donde la ciencia, impulsada por las disciplinas físico -naturales, gozaba de un espectacular prestigio. Tanto es así que el vocablo "conocimiento" ya era, como lo es hoy día, sinónimo de conocimiento científico como la única forma de conocer socialmente legitimada. Y a diferencia de lo que ocurriría en el S.XX el modelo de ciencia, al que aquí se ha 
venido llamando clásico, tradicional, oficial u objetivista, no había sido siquiera discutido en sus supuestos. Una idea de ciencia que pretende un conocimiento objetivo, racional, progresivo, acumulativo y universal. Y se ocupa de contrastar enunciados que describen el mundo observable a través de la relación empírica de propiedades. Ya no interesan tanto las definiciones, las clasificaciones, las esencias, como en la escolástica de la edad media, sino las relaciones entre propiedades observables, las variables.

La gran ideología que sostiene a este modelo clásico de ciencia moderna es que la realidad puede pensarse a través de variables, mejor dicho, a través de la estructura de relaciones entre variables. Estas variables son independientes del sujeto que las conoce de aquí que se trata de una posición epistemológica objetivista. A partir de esta concepción del conocimiento científico, que implica una manera particular de considerar la realidad, va a surgir el problema del método.

La ciencia clásica siempre ha aceptado un único método. En un principio, como ya se ha visto, fue el método verificacionista sustentado por una lógica inductiva y a partir de la obra de Karl Popper fue un método falsacionista apoyado en la lógica deductiva. Pero en ambos casos el método único tiene el deber de satisfacer esta idea de realidad pensada a través de estructuras de variables objetivas a través de cuya relación puede leerse el mundo. El método, entonces es, tanto para los verificacionistas inductivos como para los falsacionistas deductivos, la única manera de controlar impersonalmente las variables. Para el falsacionismo popperiano, la versión actual de la ciencia clásica, las hipótesis son las conjeturas que responden a un problema de investigación que surge a partir de una relación observable entre variables. La crítica a estas hipótesis, el momento clave donde puede producirse la ciencia, ha de hacerse siempre de manera impersonal para satisfacer el requisito de la objetividad. El método único entonces ha de permitir el control impersonal entre variables.

La satisfacción a esta necesidad de control impersonal entre variables por parte de un método, era clara, al momento del surgimiento de las primeras ciencias sociales, desde hacía por lo 
menos 300 años: el experimento. ¿Pero cómo se satisfacía esta necesidad en las ciencias sociales?

Resultaba claro, debido a la imposibilidad de realizar experimentos en las disciplinas sociales, que si la ciencia ha de definirse por su método aparecía un gran problema para las nuevas disciplinas. Estos problemas, frente a los que se han ensayado distintas respuestas, permanecen vigentes al día de hoy, más allá de que de acuerdo a la tesis $\mathrm{N}^{0} 3$ de éste artículo haya predominado finalmente una respuesta.

Es posible establecer cuatro respuestas principales que se le han dado a la problemática del estatuto de las disciplinas sociales: 1) no son ciencias; 2) sólo podrían ser ciencias si copian el modelo de las disciplinas físico -naturales utilizando metodologías cuantitativas;3) son ciencias pero distintas a las físico- naturales y utilizan una metodología propia; y4) no son ciencias pero se reivindica esto; hay pluralidad de métodos y todas las formas de conocimiento tienen igual estatus.

La primera respuesta es bien clara, las ciencias sociales no son ciencias. El motivo es la imposibilidad de experimentar lo que no permitiría ninguna manera de controlar impersonalmente las hipótesis. No hay por tanto relación con las ciencias físico -naturales y se trata de un conocimiento inferior. La segunda respuesta es que las ciencias sociales son ciencias pero inmaduras y que han de copiar el modelo de las ciencias físico -naturales. La solución frente a la imposibilidad de la experimentación es la utilización de métodos cuantitativos que permitirían algún tipo de control de las variables de modo impersonal. El conocimiento logrado tiene el estatus del conocimiento científico por lo que es superior a otras formas de conocimiento pero es de menor calidad al obtenido por las ciencias físico- naturales. Los métodos cuantitativos, entonces, aparecen como lo más cercano que existe a un experimento para controlar la correlación entre variables y son, por tanto, lo que permite a las ciencias sociales, ser ciencias ${ }^{7}$. La tercera respuesta es que las ciencias sociales son ciencias pero de un

\footnotetext{
${ }^{7}$ El Coeficiente de correlación de Pearson,por ejemplo, es uno de los más claros sucedáneos del
} experimento y ha sido considerado una llave para la cientifización de las CS. sociales. 
tipo distinto; ha habido distintas propuestas en este sentido pero en todas sostenían que por las características propias del estudio de lo social las ciencias sociales deberían usar sus propios métodos que en general implicaban el uso de metodologías de orden cualitativo. El estatus del conocimiento obtenido no sólo obtenía la dignidad de ser de tipo científico sino que podía competir en calidad con el de las ciencias físico- naturales. La cuarta respuesta es que las disciplinas sociales no son científicas lo cual es asumido sin problemas y sin la idea de que esto le quite calidad a su conocimiento.

Esquemáticamente se clasificarán en el cuadro $\mathrm{N}^{\circ} 4$ estas principales respuestas frente al problema de la cientificidad de las disciplinas sociales en relación con la cuestión del método, su relación con las ciencias físico -naturales y con la valoración social.

\section{Cuadro $\mathrm{N}^{\circ} 4$}

\begin{tabular}{|c|c|c|c|c|}
\hline \multicolumn{5}{|c|}{ Problemática del Estatuto de las Disciplinas Sociales } \\
\hline $\begin{array}{c}\text { Respuesta } \\
\mathrm{N}^{\mathrm{o}}\end{array}$ & Cientificidad & Método & $\begin{array}{l}\text { Relación con las Cs. } \\
\text { Físico -naturales }\end{array}$ & Valoración \\
\hline 1 & no son cs. & imposibilidad & ninguna relación & conocimiento de tipo \\
\hline
\end{tabular}




\begin{tabular}{|l|l|l|l|l|}
\hline & & experimentar & & inferior \\
\hline 2 & son cs. & Cuantitativo & Imitación & $\begin{array}{l}\text { conocimiento de tipo } \\
\text { superior }\end{array}$ \\
\hline 3 & son cs. & Cualitativo & Autonomía & $\begin{array}{l}\text { conocimiento de tipo } \\
\text { superior }\end{array}$ \\
\hline 4 & no son cs. & Pluralidad & ninguna relación & $\begin{array}{l}\text { conocimiento de tipo } \\
\text { distinto }\end{array}$ \\
\hline
\end{tabular}

Estas cuatro respuestas que en la realidad se han dado y aún se siguen dando a través de distintas propuestas y posturas concretas (en la forma de escuelas, posiciones epistemológicas de autores individuales y tradiciones de investigación) siempre han coexistido y lo han hecho bajo forma de lucha. Una lucha que incluye pero además excede la mera concepción de ciencia y que también es una lucha por una posición de dominio en el campo de la comunidad científica y que por lo tanto ha cobrado la forma de competencia por los incentivos que otorga este campo (prestigio, dinero; etc.); pero que además ha tomado la forma de un enfrentamiento ideológico porque a cada posición se le ha asignado, de manera lineal y a veces prejuiciosamente, una posición política propia.

La periodización del predominio en la historia de las ciencias sociales de una u otra postura epistemológica podría hacerse de la siguiente manera: Tras una primer debate que se produce en los inicios de la ciencia social institucionalizada (finales del S. XIX y principios del S.XX) se produce, hacia 1920 una hegemonía de la concepción de ciencia social que toma como modelo a las ciencias físico - naturales y que plantean una metodología cuantitativa. Lo que aquí se ha llamado la respuesta $\mathrm{N}^{\circ} 2$. Esta concepción cobra mayor fuerza hacia el fin de la segunda guerra mundial de la mano de la llamada revolución conductista ${ }^{8}$. A esta concepción de la ciencia social se la ha llamado "consenso ortodoxo"; "tradición heredada"10; "ciencias sociales empíricas"11. Hacia 1970 entra en fuerte crisis cuestionada por una concepción que desde distintos lugares cuestiona los supuestos epistemológicos objetivistas y los supuestos políticos e

\footnotetext{
${ }^{8}$ El estudio del comportamiento beheaviourismo.

${ }^{9}$ Antony Guidens.

${ }^{10}$ Hilary Putnam - Frederick Suppe.

${ }^{11}$ Gino Germani.
} 
ideológicos positivistas de esta concepción. Sin embargo esta crisis no logra terminar con aquella concepción y lo que se inaugura es un período donde toda la producción en ciencias sociales es atravesada por una feroz disputa epistemológica a la que se la ha denominado guerra paradigmática. Esta etapa renueva las viejas discusiones de siempre y se encierra en debates que nunca fueron saldados (objetividad / subjetividad; ciencias sociales / ciencias naturales, neutralidad valorativa / compromiso; etc.) y en lo metodológico se vuelve a disputar entre las herramientas cuantitativas y las cualitativas. A finales del S. XX se observa un relajamiento de esta guerra paradigmática; los investigadores ya no se inscriben con claridad en uno u otro paradigma. Comienzan a aparecer una mayoría de investigaciones que intentan recuperar dos tradiciones epistemológicas distintas; las objetivistas y las interpretativistas. Se piensa ya más en soluciones metodológicas que en problemas epistemológicos y se propone la triangulación metodológica ${ }^{12}$ a esta etapa se la ha denominado "pluralismo pragmático"13.

El siguiente cuadro $\mathrm{N}^{0} 5$ representa las características principales de los distintos períodos que han atravesado las ciencias sociales.

Cuadro $\mathrm{N}^{\circ} 5$

\begin{tabular}{|l|l|l|l|}
\hline \multicolumn{4}{|c|}{ Concepción de las ciencias sociales institucionalizadas } \\
\hline Etapa & $\begin{array}{l}\text { Período } \\
\text { aproximado }\end{array}$ & $\begin{array}{l}\text { Concepción } \\
\text { epistemológica }\end{array}$ & Metodología \\
\hline Consenso Ortodoxo & $1920-1970$ & objetivismo & Cuantitativa \\
\hline Guerra Paradigmática & $1970-1990$ & $\begin{array}{l}\text { lucha } \\
\text { objetivismo/subjetivism } \\
\text { o }\end{array}$ & $\begin{array}{l}\text { Lucha cuantitativa / } \\
\text { cualitativa }\end{array}$ \\
\hline Pluralismo Pragmático & $1990-$ actualidad & se diluye la discusión & $\begin{array}{l}\text { Triangulación } \\
\text { metodológica }\end{array}$ \\
\hline
\end{tabular}

\footnotetext{
${ }^{12}$ Utilización complementaria de métodos cualitativos y cuantitativos.

${ }^{13}$ Ray Pawson.
} 
Esta periodización que acaba de presentarse es, sin embargo, relativizada en el presente artículo. Relativizada al punto de que, si bien se acepta las injerencias que produjeron en el campo de las ciencias sociales las posturas subjetivistas en los distintos períodos señalados, se sostiene (tesis 3) que en última instancia siempre han dominado las posiciones objetivistas y que aún lo hacen en la actualidad. Por lo tanto el denominado pluralismo pragmático es, a efectos prácticos, virtualmente nulo. En todo caso las fuertes y muchas veces acertadas críticas que se le han hecho a las posturas objetivistas durante la denominada "guerra paradigmática" han tenido el efecto de diluir la discusión explícita sobre la epistemología de las ciencias sociales y han conseguido que sea difícil por parte de los investigadores sociales asumir de manera declarada sus supuestos objetivistas criticados tan aceradamente. Sin embargo estos se siguen operando en al menos tres dimensiones que aquí serán denominadas: dimensión concreta; dimensión política y dimensión simbólica.

a) Dimensión concreta: son las instrucciones o receta única para hacer ciencia social; responde a una matriz que se utiliza de manera estándar para la investigación. Cómo ejemplos pueden tomarse las pautas para proyectos de investigación; trabajos científicos; etc. Que exigen las instituciones que oligopolizan la producción de conocimiento científico y que siendo prácticamente idénticas pueden estandarizarse en protocolos únicos ${ }^{14}$.

b) Dimensión política: refiere al hecho de que el prestigio científico de cualquier investigación y aún las posibilidades de obtener financiamiento económico aumenta, proporcionalmente a la cantidad de hipótesis observacionales enunciadas; al uso de abordajes cuantitativos con posibilidad de contrastación empírica y a la utilización de los conceptos y herramientas propios de una concepción objetivista.

\footnotetext{
${ }^{14}$ Ver infra, pag. 4, cuadro $\mathrm{N}^{\circ} 1$.
} 
c) Dimensión simbólica: se trata del peso simbólico de todas las referencias a las características objetivistas de la ciencia. Las mismas otorgan estatus a las disciplinas: contrastación, acumulación, leyes, hipótesis, etc. Tómese como ejemplo la aceptación general, aún por las líneas epistemológicas que descartan la clásica noción de progreso científico negando así la idea de acumulación progresiva del conocimiento, de que es indispensable incluir en las bibliografías de las producciones científicas textos actuales, siendo inadmisible la presentación de trabajos que no incluyan referencias bibliográficas hiperactualizadas, despuntando así cierta inconsistencia lógica.

\section{La ciencia es producto de instituciones}

En última instancia, la ciencia se hace tangente a través de investigaciones concretas. Y estas investigaciones nunca son el producto aislado de un investigador. Cualquier producción científica sólo es considera como tal si está avalada por alguna institución académica reconocida que la acredite. Estas instituciones son las únicas que pueden producir conocimiento científico y conforman un conjunto más bien pequeño, se trata de las universidades; consejos de investigación y fundaciones científicas públicas o privadas. Estas instituciones quienes oligopolizan la producción científica (tanto en las disciplinas físico -naturales como en las sociales) más allá de las posturas epistemológicas individuales de algunos de sus miembros, utilizan de manera institucional y oficial protocolos de investigación no sólo prácticamente idénticos sino alineados, casi sin matices dentro de un modelo monológico de características similares a las propuestas por el falsacionismo popperiano qué, cómo aquí se sostiene, responde en sus características generales el modelo tradicional, objetivista de la ciencia clásica moderna.

\section{Palabras finales}

Los interrogantes que aparecen tras el planteo de las tres tesis del presente artículo trascienden sin duda a la persona de Karl Popper. Remiten, más bien a la cuestión inquietante de si la 
ciencia hoy, al margen de las distintas disciplinas, es un único producto que responde a un proyecto hegemónico con lógicas implícitas de las que no es posible desprenderse más allá de los matices. Los marcos institucionales que la promueven y desarrollan no parecen demasiados flexibles. Los abordajes dialógicos interpretativistas parece institucionalmente acorralados. ¿Cuál es el papel de las ciencias sociales? ¿Tienen un espacio de libertad mayor en cuanto a su fundamentación epistémica? ¿Tienen la posibilidad de resignificar a las otras ciencias? ¿Pueden responder a un proyecto que suponga una cosmovisión plural? ¿O más bien participan del modelo común de las otras ciencias? ¿Hasta qué punto? ¿Con qué poder?

\section{Bibliografía}

FEYERABEND, Paul (1974): Contra el método, Ariel, Barcelona

GADAMER, Hans (1997): Verdad y Método, Tomos I y II, Sígueme, Salamanca.

GEERTZ, Clifford:( 1987) La interpretación de las culturas, Gedisa, Barcelona.

GEERTZ, Clifford(1989): El antropólogo como autor, Paidos, Bs. As..

GIDDENS, Anthony(1987 ): Las nuevas reglas del método sociológico, Amorrortu.

HELER, M., (2009) Ciencia incierta. Buenos Aires. Biblos.

LÉVI-STRAUSS, Claude(1968): Antropología estructural, EUDEBA, Bs.As.

POPPER, Karl(1992): Sociedad abierta, universo abierto, Tecnos, Madrid.

POPPER, Karl(1994): El mito del marco común, Paidos, Barcelona. 
POPPER, Karl(1972): La responsabilidad de vivir, Paidos, Barcelona.

POPPER, Karl(1984): En busca de un mundo mejor, Paidos, Barcelona.

POPPER, Karl(1998): Los dos problemas fundamentales de la epistemología, Tecnos, Madrid.

POPPER, Karl (1982): La lógica de la investigación científica, Tecnos, Madrid.

POPPER, Karl (1973) Conjeturas y refutaciones, Paidos, Bs. As.

POPPER, Karl (1974) Conocimiento objetivo, Madrid, Tecnos.

POPPER, Karl(1985) La sociedad abierta y sus enemigos, Tomos I y II Hyspamerica, Bs. As.

POPPER, Karl(1985): Búsqueda sin término, Tecnos, Madrid,.

POPPER, Karl(1985 ): La lógica de las ciencias sociales, Grijalbo, México.

RICOEUR, Paul(1963 ): Structure et Hermeneutique, Escrit Na 11.

RICOEUR, Paul(1981 ): Ideología y utopía, Gedisa, México.

RICOEUR, Paul(1985): Freud. Una interpretación de la cultura, Siglo XXI, México.

VÁZQUEZ, Amancio(2009): “Karl Popper y Claude Lévi-Strauss. Convergencias y Analogías”, en Memorias del $53^{\circ}$ Congreso ICA, México.

WEBER, Max(1980 ): Ensayos sobre metodología sociológica, Amorrortu,.

WHEELER, Cristina(1998): “Popper. Crítica racional a la producción de conocimiento”, en cuaderno de cátedra $n^{\circ}$ 2, Facultad de Cs. Política y RRII. Universidad Nacional de Rosario. 